\title{
Study on Preparation of Lignin-Containing Nanocellulose from Bamboo Parenchyma
}

\author{
Wenli Gu ${ }^{1}$, Shiyi Zeng ${ }^{1}$, Assima Dauletbek ${ }^{2}$, Bin $\mathrm{Xu}^{1,3,{ }^{*}}$, Xinzhou Wang ${ }^{1}$, Man Yuan ${ }^{1}$ and Yanni Gu ${ }^{1}$ \\ ${ }^{1}$ College of Materials Science and Engineering, Nanjing Forestry University, Nanjing, 210037, China \\ ${ }^{2}$ College of Civil Engineering, Nanjing Forestry University, Nanjing, 210037, China \\ ${ }^{3}$ Bamboo Engineering and Technology Research Center, State Forestry and Grassland Administration, Nanjing, 210037, China \\ *Corresponding Author: Bin Xu. Email: xubinberc@163.com
}

Received: 07 March 2021 Accepted: 26 April 2021

\begin{abstract}
Bamboo vascular bundle fiber and parenchyma (BP) are separated by high-temperature treatment with saturated steam. Bamboo vascular bundle fiber is widely used in the market, but how to develop and utilize parenchyma tissue is a difficult problem. The sulfated cellulose nanofibers (ANFs) were obtained by sulfating BP with a deep eutectic solvent (DES), which provided a theoretical basis for the value-added utilization of BP. Using DES as the reaction medium and reagent, the BP was grafted with a sulfonic acid group to form a gel substance in water, ANFs and nanocellulose gel were obtained by ultrasonic cell crusher. The highest yield of ANFS was $75 \%$. The width of the ANFs was about $3 \mathrm{~nm}$, and a small number of nanofiber aggregates existed at the same time. A high aspect ratio of ANFs, due to their high viscosity, has potential applications as enhancers at low concentrations. Lewis acid $\left(\mathrm{ZnCl}_{2}\right)$ added based on binary (DES) greatly improved the thermal stability of the ANFs and maintained the crystal form of cellulose I.
\end{abstract}

\section{KEYWORDS}

Lignin; nanocellulose; deep eutectic solvent; bamboo; saturated steam heat treatment; parenchyma

\section{Introduction}

The depletion of fossil resources is inevitable and brings serious environmental, economic and social problems. The search for renewable, sustainable materials and energy is a top priority. New reinforcement techniques [1], passively controlled structural systems [2,3], wood, and bamboo as a sustainable green building material, are attracting more attention from the construction sector [4-8]. Bamboo is one of the fast-growing and most productive renewable natural resources in the world and has a high growth rate in the growing season $[9,10]$. Among plants, bamboo is the most important material-producing variety that is planted over large areas. Because of its fast growth, excellent strength, and conversion ability, it is widely used in pulping, construction, spinning, and other industries. In addition, it can be used to produce bioethanol, bio-methane, natural foods, flavonoids, composites, and functional nanomaterials [11]. The development and utilization of Phyllostachys pubescens can effectively promote the industrial utilization of biomass. At present, the industrial production of Phyllostachys pubescens is increasing year by year, and the waste residue is burned or discarded in large quantities, which produces great pressure on the 
environment. It is necessary to promote the transformation of Phyllostachys pubescens into high-value and biological-based products. In the previous investigation, the research group used the high-temperature saturated steam method to treat bamboo, and mechanically separated the bamboo fiber bundle to obtain it with good performance, while the remaining part of the fiber bundle was wasted because of the complex composition and difficult use [12]. If the resources that should have been discarded can be reused, it is not only in line with sustainability, but can also contribute to the development and utilization of biomass.

At present, most of the raw materials for preparing nanocellulose are pulp, such as bleaching birch pulp [13] Cotton fibre [14] cork soluble cellulose pulp [15] and almost all cellulose with low lignin content [16]. The turbid gel cellulose nanofiber suspension with an average spherical diameter of $262 \mathrm{~nm}$ was obtained from Ramie fiber by two systems of choline chloride oxalate dihydrate (CO) and choline chloride urea (CU) in the study. Hong et al. [17] pretreated birch fiber with betaine hydrochloride and glycerol to obtain $72.5 \%$ of high-yield nanocellulose fiber (CNF). Song et al. [18] extracted Nanocellulose from loofah collaterals and thin films with high tensile strength (134 MPa). Herrera et al. [19] successfully isolated nanocellulose with a lignin content of $23 \%$ from eucalyptus wood pulp (LCNFs) by catalytic chemical oxidation and high-pressure microfluidic technology. Using ball mill and ultrasonic aid, the nanofibers prepared with sunflower stem fiber as raw material contained $76 \%$ of lignin, and the ultrathin nanofilms were prepared, and the hydrophilicity was lower than that of traditional cellulose nanomaterials.

The pretreatment of nano-cellulose is an essential step to reduce the crystallinity of cellulose, increase the accessibility and porosity of biomass materials, release more available substrates, and improve the utilization of cellulose [20]. There are generally four methods of pretreatment: physical (mechanical grinding, pyrolysis irradiation), chemical (acid, alkali, and organic solvents, ozone, ionic liquid), physical and chemical (steam blasting, fiber blasting, wet oxidation), biological (fungal pretreatment, bacterial pretreatment, termites pretreatment, enzyme pretreatment) [21,22]. These methods are to pave the way for subsequent steps. However, conventional physical and chemical pretreatment methods need high energy consumption and professional corrosion resistance, and high-pressure equipment. Post-treatment also requires relatively complex operations such as detoxification of raw materials, which not only pollutes the environment but is also relatively expensive. Although the reaction conditions of the biological method are mild and the energy consumption is small, it needs a long process and strict requirements for the system environment. Moreover, the solvents used in traditional methods in large quantities (volatile, reactive, phase solubility, etc.) and environmental problems. The development of new, green, and inexpensive solvents as pretreatment agents has become one of the most important research directions in recent years. A deep eutectic solvent (DES) is the most promising solvent to meet this need [23].

DES is a green solvent consisting of a hydrogen bond acceptor and another hydrogen bond donor (HBD). DES has low vapor pressure, has good solvent potential, and is recoverable under best conditions [24]. In organic synthesis and biomass processing, DES has been studied as a solvent [25], reagent [26], and catalyst [27]. Jiang [28] proposed an ternary DES system for the production of lignin-containing cellulose nanocrystals from coniferous wood thermal mechanical pulp, and sulfated cellulose was prepared from DES containing p-toluenesulfonic acid. The DES system of long nanofiber bundles was successfully prepared by choline chloride and urea system [29]. The length of cellulose nanofibers can reach $15-200 \mathrm{~nm}$, and the width is $2-5 \mathrm{~nm}$. Due to the hydrogen bonding and dense structure of cellulose fibers embedded in a strong lignin matrix, the liberation of nanofibers from woody biomass is a tedious process and requires a lot of energy [30,31]. Bian et al. [32] proved the feasibility of p-toluenesulfonic acid (p-TSOH) acidolysis of wood fibers. Cellulose nanofibers (LCNFs) containing lignin were prepared with the values of height of CNFs $(10.6-86.4 \mathrm{~nm})$ and excellent thermal stability to produce biodegradable composites. 
The obvious disadvantage of sulfated cellulose is its poor thermal stability, which limits its use in the production of nanocomposites. The improvement of thermal stability of pure sulfated cellulose needs further study. Lewis acid is one of the ways to improve thermal stability [33]. The addition of halogen atoms promotes the formation of hydrogen bonds, the connection of cross-linked networks, and thermal stability. In addition, the presence of lignin also enhanced the thermal stability of the material.

In this study, sulfated cellulose was obtained by using the DES, a mixture of sulfamic acid and urea as a pretreatment before mechanical disintegration. Among the DES systems used by other researchers, it is difficult to retain lignin with content greater than $35 \%$ unless ground by ball mill and this system can retain lignin to a great extent. The delignification rate is discussed from temperature and reaction time. The fibers obtained after DES pretreatment were characterized by transmission electron microscopy (TEM), Fourier transform infrared spectroscopy (FTIR), X-ray diffractometer (XRD), and thermogravimetric analysis (TG) measurements. Moreover, for the first time, a simple method was obtained to introduce Lewis based on binary DES to improve the thermal stability of sulfonic acid nanocellulose. A transmission electron microscope (TEM), x-ray diffraction, and thermogravimetric analyzer were used to characterize the morphology, crystallinity, and thermal stability of the product, respectively.

\section{Materials and Method}

\subsection{Materials}

Moso bamboo (Phyllostachys edulis), a five-year-old fresh Phyllostachys heterocycla harvested from Qingyuan, Zhejiang, were treated with saturated steam at $180^{\circ} \mathrm{C}$ in $40 \mathrm{~min}$. After the fiber bundle was separated by mechanical compaction, any remaining powdery substance (BP) was sieved in an 80 mesh sieve (Shangyu Dadi Sampling Screening Factory, China), and dried in the oven (Shanghai Jinghong Experimental Equipment Co., Ltd., China) for $12 \mathrm{~h}$ under $60^{\circ} \mathrm{C}$. Amino sulfonic acid (SA), urea (UR), $\mathrm{ZnCl}_{2}$ were purchased from Chinese Medicine Group Chemical Reagent Co., Ltd., Shanghai, China. Distilled water (homemade) was used throughout the experiment and all chemicals were of the reagent grade. The preparation process is shown in Fig. 1.

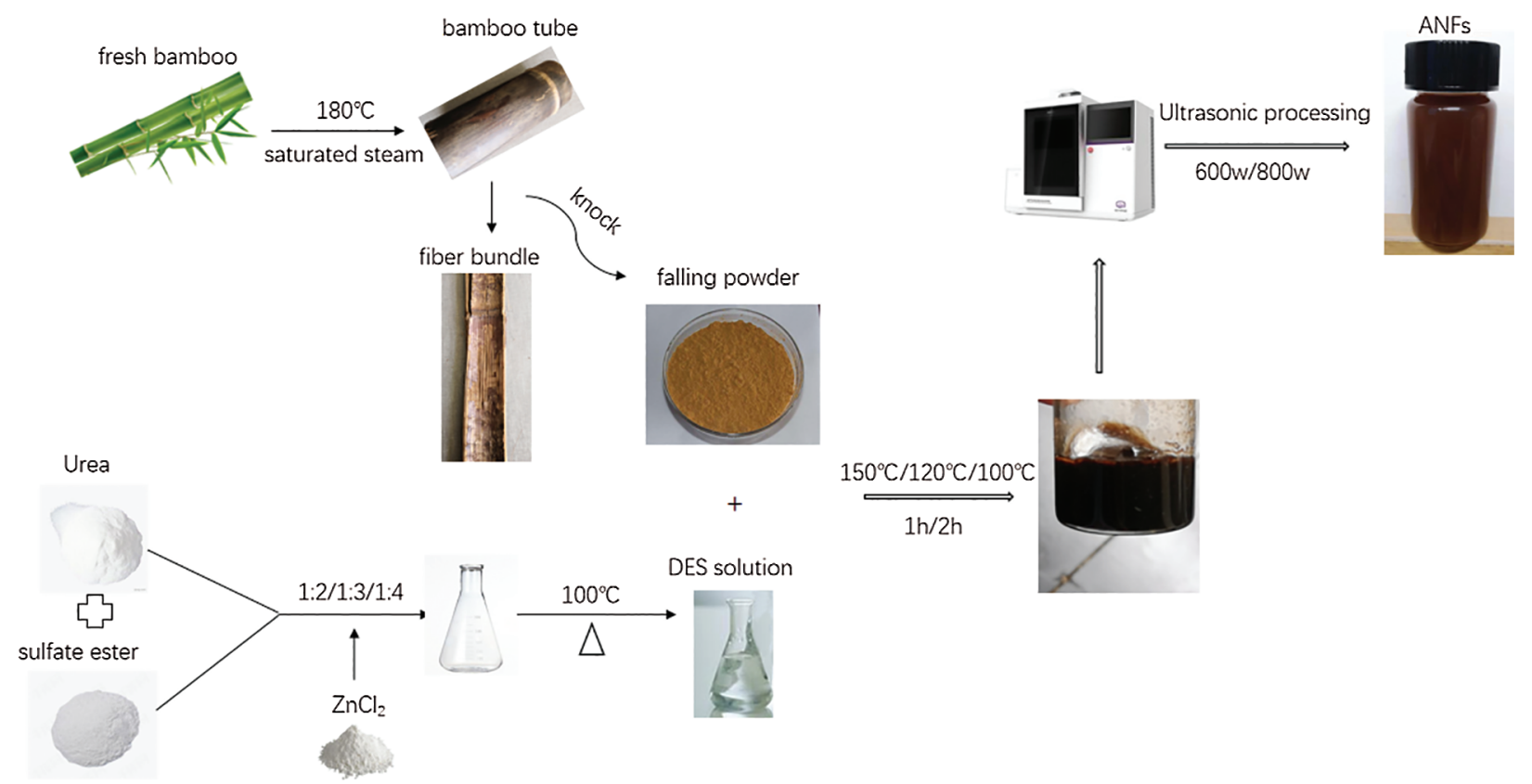

Figure 1: Flow chart of sample preparation 


\subsection{Synthesis of DES and Pretreatment of BP}

The components of DES were mixed with a magnetic agitator in an oil bath at $80^{\circ} \mathrm{C}$ at a molar ratio of 1:4, 1:3, or 1:2 (sulfonic acid: urea), while Lewis acid $\left(\mathrm{ZnCl}_{2}\right)$ was introduced and mixed with SA at a molar ratio of $0.2 \%$ to 1 until a clear solution was obtained (approximately half an hour) (see Tab. 1 for details). The mixture was magnetically stirred for $30 \mathrm{~min}$ in a $100^{\circ} \mathrm{C}$ oil bath to get color and transparent liquid. After pretreatment in a dry, clean conical flask, the quantity and DES ratio of the added BP was 1:10 of the mass ratio. The amount and DES ratio of thin wall tissue (BP) of Phyllostachys pubescens treated with high-temperature saturated steam was $1: 10$ of mass ratio. Then, the heating was conducted at $100^{\circ} \mathrm{C}$, $120^{\circ} \mathrm{C}$, and $150^{\circ} \mathrm{C}$, and holding time constituted $1 \mathrm{~h}$ or $2 \mathrm{~h}$ in total. After the reaction, the system was removed from the oil bath, distilled water was added to quench the reaction. After each pretreatment, all samples were filtered in a vacuum and washed with water until the $\mathrm{pH}=7$ of the filtrate. Then, solids were collected and different volumes $(100,150$ and $200 \mathrm{ml})$ of deionized water were added to obtain different concentrations of suspensions.

Table 1: DES synthesis and pretreatment under different conditions

\begin{tabular}{llllllll}
\hline Sample & $\begin{array}{l}\text { SA:Urea: } \\
\mathrm{ZnCl}_{2} \\
(\mathrm{molar}\end{array}$ & $\begin{array}{l}\mathrm{BP}: \mathrm{DES} \\
(\mathrm{w} / \mathrm{w})\end{array}$ & $\begin{array}{l}\left(/{ }^{\circ} \mathrm{C}\right) \\
\text { reaction } \\
\text { temperature }\end{array}$ & $\begin{array}{l}\text { Reaction } \\
\text { time }(/ \mathrm{h})\end{array}$ & $\begin{array}{l}\text { Frequency of } \\
\text { ultrasound }(/ \mathrm{w})\end{array}$ & $\begin{array}{l}\text { Ultrasound } \\
\text { time }(/ \mathrm{min})\end{array}$ & $\begin{array}{l}\text { Suspension } \\
\text { concentration } \\
(/ \mathrm{wt} \%)\end{array}$ \\
\hline 1 & $1: 2: 0$ & $1: 10$ & 150 & 1 & 800 & 10 & 1 \\
2 & $1: 3: 0$ & $1: 10$ & 150 & 1 & 800 & 10 & 0.75 \\
3 & $1: 4: 0$ & $1: 10$ & 150 & 1 & 800 & 10 & 0.5 \\
4 & $1: 3: 0$ & $1: 15$ & 150 & 1 & 800 & 10 & 0.5 \\
5 & $1: 3: 0$ & $1: 20$ & 150 & 1 & 800 & 10 & 0.5 \\
6 & $1: 3: 0$ & $1: 10$ & 120 & 1 & 800 & 10 & 0.5 \\
7 & $1: 3: 0$ & $1: 10$ & 120 & 2 & 800 & 10 & 0.5 \\
8 & $1: 3: 0$ & $1: 10$ & 100 & 1 & 800 & 10 & 0.5 \\
9 & $1: 3: 0$ & $1: 10$ & 150 & 1 & 600 & 15 & 0.5 \\
10 & $1: 3: 0$ & $1: 10$ & 150 & 1 & 500 & 20 & 0.5 \\
11 & $1: 3: 0$ & $1: 10$ & 150 & 1 & 800 & 10 & 0.5 \\
12 & $1: 3: 0.2$ & $1: 10$ & 150 & 1 & 800 & 10 & 0.5 \\
\hline
\end{tabular}

\subsection{Major Chemical Composition Analysis}

After pretreatment, the samples were numbered according to different reaction conditions and dried in the oven to constant weight under $60^{\circ} \mathrm{C}$. American National Renewable Energy Laboratory (NERL) [34,35]. The analysis of chemical composition of powder samples before DES pretreatment was made using highperformance liquid chromatography (Agilent1260) the determination of sugar was made by BioRadAminexHPX-87H column $(300 \mathrm{~mm} \times 7.8 \mathrm{~mm})$ using Bio-Rad (USA), under $55^{\circ} \mathrm{C}, 5 \mathrm{mM}$ sulfuric acid was used as the mobile phase $(0.6 \mathrm{~mL} / \mathrm{min})$.

\subsection{Preparation of Anionic BP Nanofibers}

The pretreated samples (not dried) were diluted to a concentration of $0.5 \%$ in distilled water. The suspension was subjected to fiber tremor by ultrasound to obtain uniformly dispersed anions of BP 
nanofibers (ANFs). The ultrasonic frequency was 800,600 and $500 \mathrm{w}$, the ultrasonic time was 10, 15 and 20 min, respectively.

\subsection{Determination of Zeta Potential and Particle Size}

The particle size distribution and Zeta potential of nanoparticles were determined by Malvern Zeta sizer $3000 \mathrm{HS}$ laser particle size meter by diluting the ANFs with distilled water.

\subsection{Infrared Spectrometric Test}

The original BP and sulfonic BP were chemically characterized by an infrared spectrometer. AVERTEX $80 \mathrm{~V}$ spectrometer (Germany) was used to collect the spectra from the freeze-dried samples. The spectra were determined by $\mathrm{KBr}$ pressing method at the range of $400-4000 \mathrm{~cm}^{-1}$, and resolution of $4 \mathrm{~cm}^{-1}$ with 128 scans per sample. Analysis of changes in chemical bonds and functional groups was conducted after pretreatment of raw materials, baseline correction of all obtained spectra, and removal of interference peaks [36].

\subsection{ANFs Morphological Analysis}

Transmission electron microscopy JEM-1400 (Japan) was used to analyze the morphological characteristics of the prepared ANFs. Each sample was prepared by diluting with distilled water (0.05\%), and carbon-coated copper grids were prepared by poly-lysine coating for $2 \mathrm{~min}$. Small droplets of $0.1 \%$ poly-lysine solution were placed at the top of the mesh. Then a small drop of the diluted ANFs sample was placed at the top of the mesh with uranyl acetate $(2 \% \mathrm{w} / \mathrm{v}$ in water) as a negative dye. The mesh was dried under a sodium lamp and analyzed under standard conditions of $200 \mathrm{kV}$. Image J software was used to measure ANFs dimensions.

\section{$2.8 X R D$}

The crystal structure of the original BP and ANFs was studied by wide-angle X-ray diffraction. The combined multifunctional horizontal Ultima IV X-ray diffractometer (Japan) was set at $200 \mathrm{kV} 45 \mathrm{~mA}$. All freeze-dried samples were pressed into sheets of $1 \mathrm{~mm}$ thick. The test was conducted under the following conditions: $\mathrm{CuK} \alpha$ ray, Ni slice filter, $\lambda=0.154 \mathrm{~nm}$, scan in the range of $2 \theta$ (Bragg angle), from 5 to $55^{\circ}$, the scan speed of $2^{\circ} \mathrm{min}^{-1}$ with a step size of 0.05 . Using MDI jade software to map analysis, crystallinity index (CrI) was calculated according to the Segal method [2].

$\operatorname{CrI}(\%)=\frac{I_{(c r y)}-I_{(a m)}}{I_{(c r y)}} * 100 \%$

where I (cry) is the crystal region strength and I (am) is the amorphous region strength.

\subsection{Thermogravimetric Analysis}

The thermogravimetric analysis of ANFs and primary BP was made using the thermogravimetric analyzer (TG209) in a nitrogen (dynamic air) atmosphere at a constant rate of $60 \mathrm{~mL} / \mathrm{min}$. About 5 dry samples were kept at room temperature, heated from 40 to $600^{\circ} \mathrm{C}$, the heating rate was $5{ }^{\circ} \mathrm{C} / \mathrm{min}$. The derivative curve of TGA (DTG) was recorded and analyzed by Origin.

\section{Results and Discussion}

\subsection{Chemical Composition Analysis}

Before pretreatment, BP cellulose was about $40 \%$, hemicellulose was about $16 \%$, lignin content was almost the same as cellulose, which belonged to biomass material with high lignin content (see Tab. 2). With the increase of the Urea molar number, some xylan and lignin components were dissolved in each DES pretreatment. When the molar ratio of SA/Urea was 1:2 (Samples 1, 2, 3), the lignin content even 
increased. The possible reason was that the oxidation of amino sulfonic acid caused the cleavage of glycoside bond and led to the depolymerization of hemicellulose. In addition to the removal of most of the hemicellulose, cellulose was partially degraded into small molecules, washed and filtered, dissolved in water, and lost [16]. The retention of high lignin content may be due to the carbonization of some raw materials because of the presence of urea, which prevents the further reaction of amino sulfonic acid. Under the same temperature, SA/Urea $=1: 3 / 1: 4$ (molar ratio), the three components were basically the same, and the yield was $75 \pm 1$, which was higher than that of choline chloride $(\mathrm{ChCl}) /$ oxalic acid $(\mathrm{OA})$ system (about 60\%) [37]. When the reaction temperature dropped to $100^{\circ} \mathrm{C}$, the same effect was achieved, and the reaction was carried out under milder conditions.

Table 2: DES Analysis results of pretreatment under different conditions

\begin{tabular}{lccccc}
\hline Sample & $\begin{array}{c}\text { hemicellulose } \\
(\%)\end{array}$ & $\begin{array}{c}\text { Cellulose } \\
(\%)\end{array}$ & $\begin{array}{c}\text { Acid soluble } \\
\text { lignin (\%) }\end{array}$ & $\begin{array}{c}\text { Acid insoluble } \\
\text { lignin (\%) }\end{array}$ & $\begin{array}{c}\text { Total } \\
\text { lignin (\%) }\end{array}$ \\
\hline BP & 16.08 & 39.40 & 2.28 & 38.86 & 41.14 \\
$150-1: 2$ & 4.60 & 41.13 & 2.01 & 40.06 & 42.07 \\
$150-1: 3$ & 4.30 & 42.63 & 1.72 & 36.31 & 38.03 \\
$150-1: 4$ & 4.30 & 43.52 & 1.61 & 35.03 & 36.64 \\
$120-1 \mathrm{~h}$ & 4.19 & 44.77 & 1.55 & 35.01 & 36.56 \\
$120-2 \mathrm{~h}$ & 3.04 & 41.92 & 1.65 & 35.02 & 36.67 \\
$100-1 \mathrm{~h}$ & 3.95 & 42.85 & 1.62 & 35.27 & 36.89 \\
$\mathrm{ZnCl}_{2}$ & 3.45 & 40.85 & 1.62 & 37.58 & 39.20 \\
\hline
\end{tabular}

\subsection{Infrared Spectrum Analysis}

The DRIFT spectra of BP and modified ANFs were observed in the infrared spectrum, as shown in Fig. 3. As a result of the hydrolysis of hemicellulose, the $\mathrm{C}=\mathrm{O}$ stretching vibration peak of the acetyl group is weakened, and the existence of this peak in the spectrum indicates that the pretreated hemicellulose is removed, which is consistent with previous studies [38]. The presence of a large number of hemicellulose acetyl groups indicates that the disappearance of the peak represents the removal of hemicellulose. At the same time, it can be seen that the efficiency of the ternary DES system (Sample 12) was high and the peak intensity is weaker. A typical $\mathrm{C}=\mathrm{O}$ stretching vibration peak of lignin aromatic ring. Furthermore, the peaks of $1330 \mathrm{~cm}^{-1}$ and $1240 \mathrm{~cm}^{-1}$ are of cloves and guaiacine groups. The greater the change in the peak, the narrower the band. This shows that some lignin has been removed from the pretreated sample, and the obtained sample still contains lignin. Levdansky et al. [39] proposed that sulfamic acid was used in the sulfation of microcrystalline cellulose with an organic solvent as the reaction medium. In the current study, sulfamic acid was used as part of the reactive DES for external solvent-free cellulose sulfating. At $1242 \mathrm{~cm}^{-1}$ and $810 \mathrm{~cm}^{-1}$, the asymmetric $\mathrm{S}=\mathrm{O}$ of sulfate groups and the skeleton vibration peak of symmetric $\mathrm{C}-\mathrm{O}-\mathrm{S}$ can be observed, the results are consistent with the conclusion drawn by Sirviö et al. [15]. In the original BP, there was no such peak, indicating that the sulfate group was grafted on cellulose to form cellulose sulfate (see Scheme 1). 
JRM, 2022, vol.10, no.2

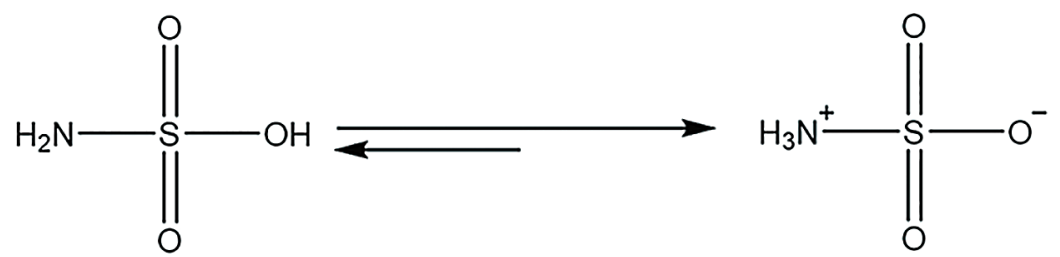

(a)

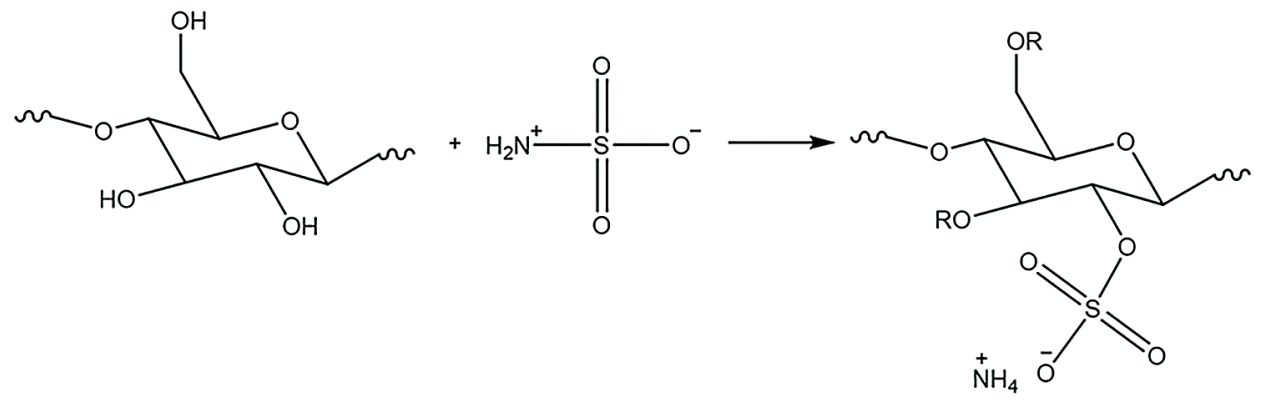

(b)

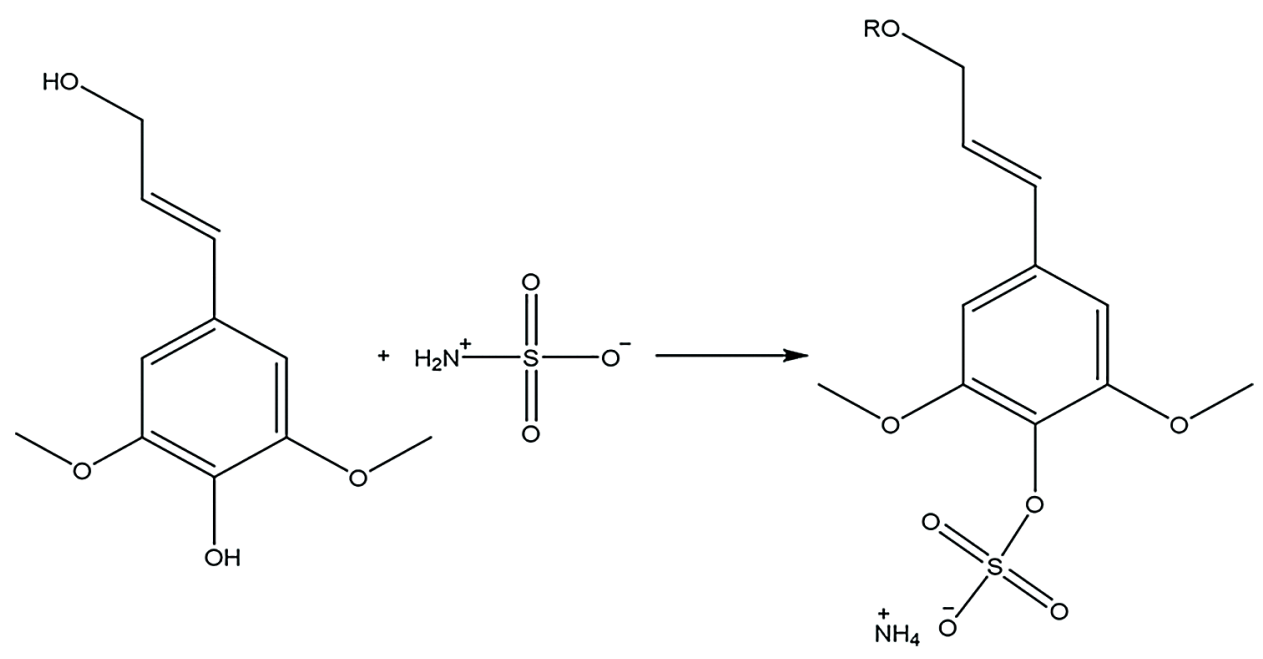

(c1)

Scheme 1: (Continued) 

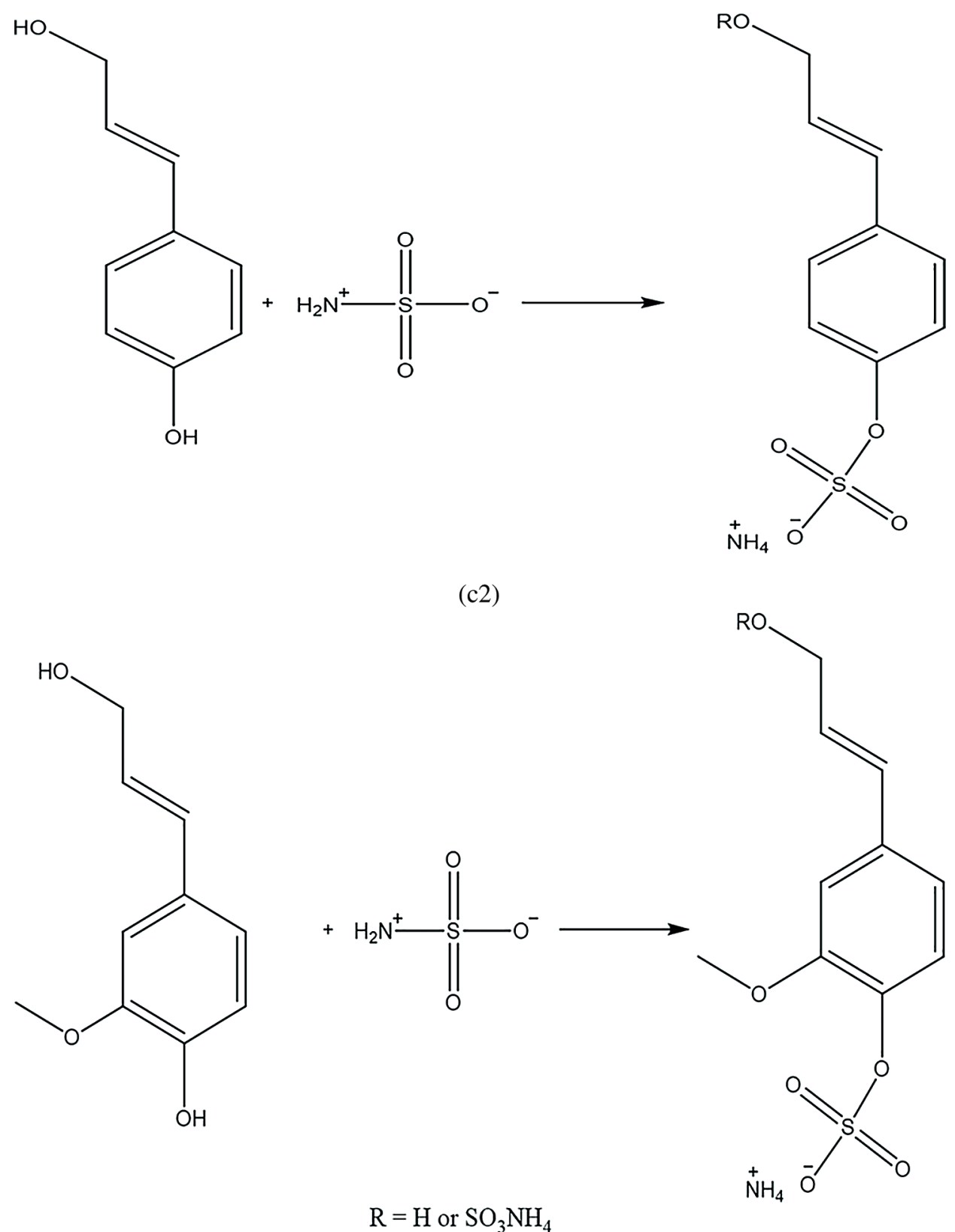

(c3)

Scheme 1: (a) two tautomers of sulfamic acid exhibit neutral (left) and zwitterionic (right) forms; (b) the reaction between sulfamic acid and cellulose; and (c) the reaction between sulfamic acid and lignin

\subsection{Transmission Electron Microscopy}

The average width of ANFs was $3 \mathrm{~nm} \pm 0.6$ as shown in Fig. 4. The diameter of the aggregates of some fibers was $10 \mathrm{~nm}$, because of the adhesion of lignin, the surface of the treated ANFs adhered to the lignin, and the lignin adhered to each other, which facilitated the formation of $\mathrm{SA} / \mathrm{Ur} / \mathrm{ZnCl}_{2}$ aggregates. According to the value of Zate potential, the prepared nanocellulose is negatively charged, and the introduction of Lewis acid also brings negatively charged chloride ions. Therefore, it is most likely that the chloride ions of zinc chloride 
bring high charge and generate electrostatic repulsion between the fibers. Lignin formed irregular nanoparticles in which the particle size was about $80 \mathrm{~nm}$, which was consistent with the test results of the particle size analysis.

\subsection{Zeta Potential and Particle Size Analysis}

The surface charge of the ANFs colloidal suspension was obtained by Zeta potential analysis. The potential of the solid/liquid interfaces of the aqueous solution was given. The Zeta potential values of the prepared ANFs suspensions are listed in Tab. 3. The ZP absolute values of the prepared ANFs under all conditions were greater than 40 , which showed good stability and carried anionic charges. When the reaction temperature was $150^{\circ} \mathrm{C}$ and the reaction time was $1 \mathrm{~h}, \mathrm{SA} / \mathrm{Ur}$ with the molar ratio 1:2(150-1:2) showed the best stability. Their distribution index was greater than 1, combined with the particle size intensity distribution (Fig. 2), ANFs had polydispersity.

Table 3: Analysis and treatment of Zeta potentials

\begin{tabular}{lcc}
\hline Types & $\mathrm{ZP} /(\mathrm{MV})$ & Dispersant RI \\
\hline $150-1: 2$ & -56.3 & 1.33 \\
$150-1: 3$ & -45.2 & 1.45 \\
$120-1 \mathrm{~h}$ & -45.4 & 1.43 \\
$120-2 \mathrm{~h}$ & -45.5 & 1.39 \\
$100-1 \mathrm{~h}$ & -45.1 & 1.57 \\
$\mathrm{ZnCl}_{2}$ & -45.6 & 1.46 \\
\hline
\end{tabular}
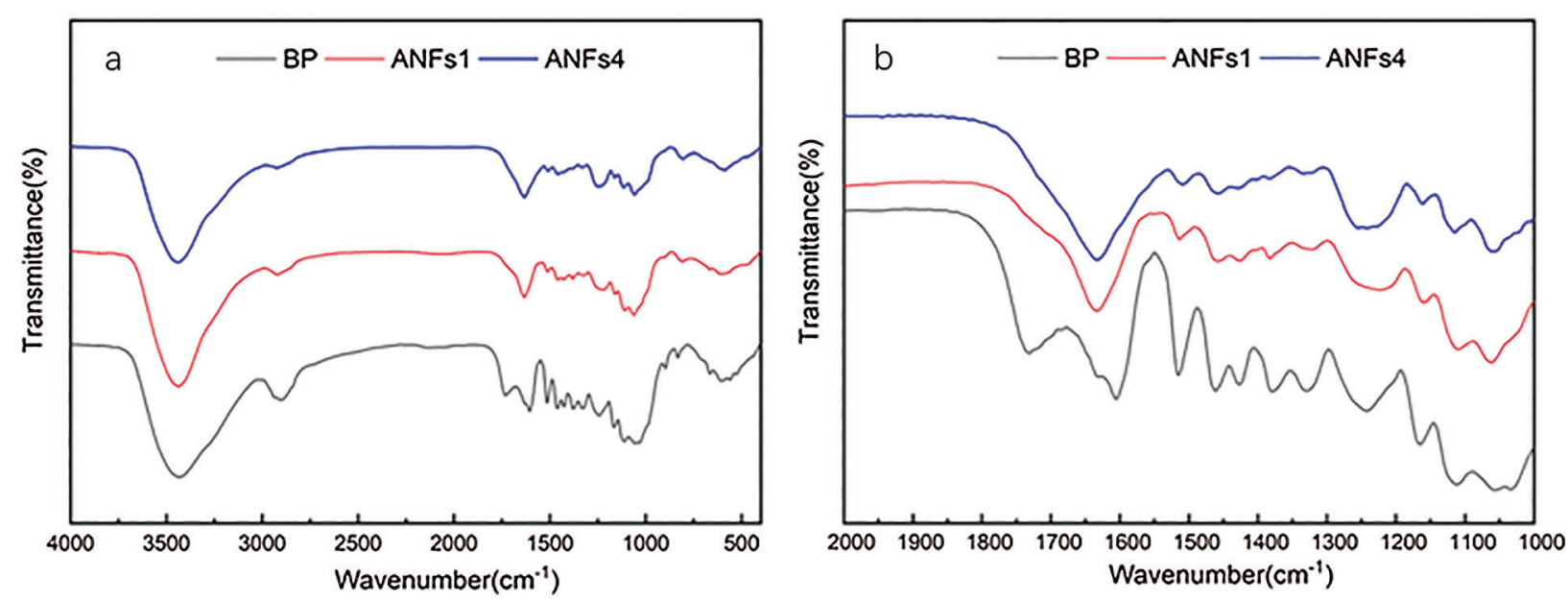

Figure 2: Fourier transform infrared spectra of ANFs. Note: (a) Among them, BP was the raw material, ANFS1 was the lignin-containing nano-cellulose in binary DES system, and ANFS4 was the product after the treatment of ternary DES system. (b) spectrum shows the difference between the two spectra 


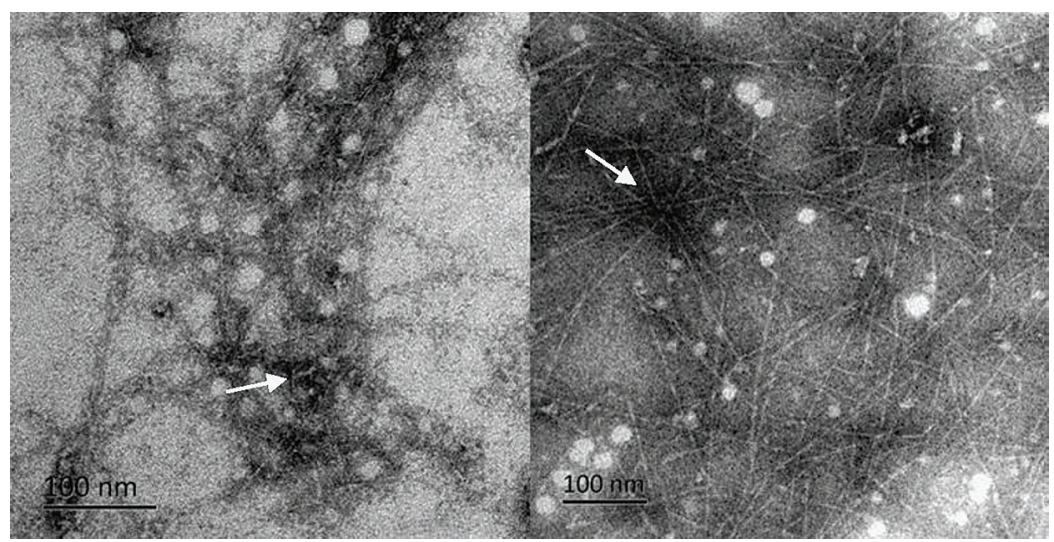

Figure 3: TEM images ANFs: ANFs, fiber aggregates prepared by binary DES 10 (left); ANFs, fiber width 3 (lignin diameter $<100 \mathrm{~nm}$ (right)
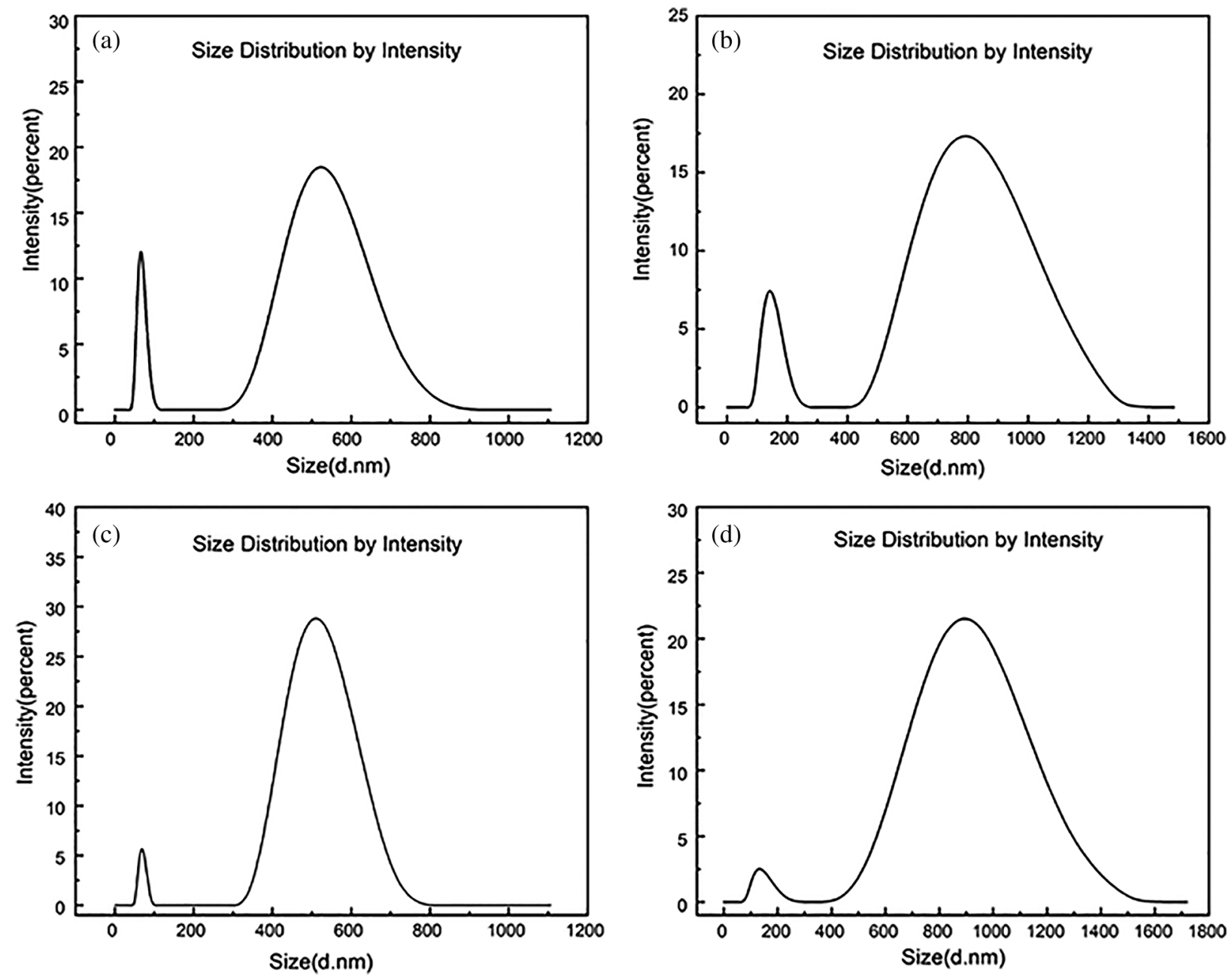

Figure 4: ANFs Particle size analysis under reaction conditions. Note: (a) $150^{\circ} \mathrm{C} / 1 \mathrm{~h}$, (b) $120^{\circ} \mathrm{C} / 1 \mathrm{~h}$, $120^{\circ} \mathrm{C} / 2 \mathrm{~h}$, (d) $100 / 1 \mathrm{~h}$ 
The smallest nanoparticle was $50.7 \mathrm{~nm}$, and the largest particle size was up to $1.2 \mu \mathrm{m}$, as shown in Fig. 2 . The results show that some lignin reached nanometer level under the system of sulfamic acid, and the micron particle was due to the adhesion of lignin to form a large particle size. With the increase of reaction temperature, it was easier to obtain particles with smaller particle sizes, and the increase of reaction time also reduced the particle size. When the reaction condition was $120^{\circ} \mathrm{C} / 1 \mathrm{~h}$, the molecular distribution curve was narrow and the particle size distribution was uniform.

\section{$3.5 X R D$}

Untreated feedstock at $22^{\circ}$ corresponding to the (002) lattice planes. There were peaks at $16^{\circ}$ corresponding to the (101) lattice planes and $34.8^{\circ}$ corresponding to the (040) lattice planes, which are typical features of cellulose I. However, the preprocessing of the binary system weakened the peak at (002), the diffraction line peak was wide and scattered, grains smaller, and the crystallinity reduced. The crystallinity decreased from $79.31 \%$ to $68.53 \%$, possibly because the amorphous dispersion of lignin affected crystallinity in the system. As shown in Tab. 4, a comparison of crystallinity of the ANFs obtained under different treatment conditions. As the reaction temperature increased, the crystallinity decreased. This finding can be interpreted as, with the introduction of DES solvent molecules into the lattice, large molecules that destroy cellulose also destroy the lattice. After introducing Lewis acid, the binary system was optimized, the separation of hemicellulose and cellulose was improved, and the original cellulose I crystal structure was well retained (Fig. 5). The ANFs obtained by ternary system treatment had peaks at $23^{\circ}$ lattice planes and 17 lattice planes. Based on Jade software processing and crystallization index (CrI) calculations, the crystallinity constituted 80.32. The addition of chloride ions led to more van der Waals forces between molecules, which made the fibers more stable and regular. In contrast to the binary system, the ternary system had higher crystallinity.

Table 4: ANFs crystallinity index (CrI)

\begin{tabular}{llllll}
\hline Types & BP & SA/Ur1 & SA/Ur2 & SA/Ur3 & SA/Ur2/Zn \\
\hline CRI/\% & 79.31 & 68.53 & 60.00 & 58.27 & 80.32 \\
\hline
\end{tabular}

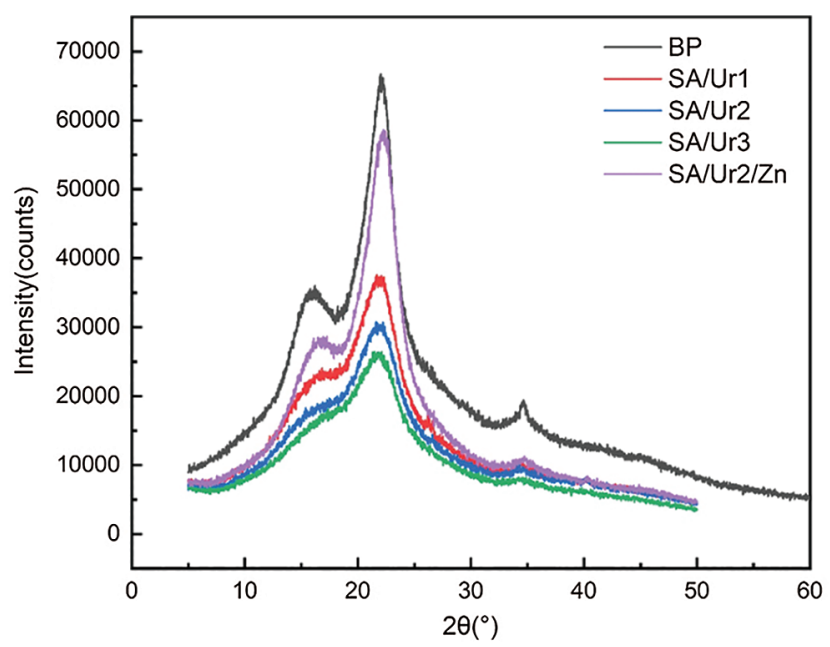

Figure 5: $\mathrm{BP}$ and ANFs $\mathrm{X}$ diffraction patterns. Note: $\mathrm{SA} / \mathrm{Ur} 1, \mathrm{SA} / \mathrm{Ur} 2, \mathrm{SA} / \mathrm{Ur} 3100^{\circ} \mathrm{C}, 120^{\circ} \mathrm{C}, \mathrm{ANFs}$, under $150^{\circ} \mathrm{C}$ conditions $\mathrm{SA} / \mathrm{Ur} 2 / \mathrm{Zn}$ ANFs obtained under $150^{\circ} \mathrm{C}$ of ternary DES system 


\subsection{TGA}

The thermal stability of the original material BP and ANFs is shown in Fig. 6. As can be seen from Fig. 6, BP degradation temperature starts from $180^{\circ} \mathrm{C}$, and the highest mass loss rate is $22 \%$. It shows that the initial reaction temperature of ANFS is $200^{\circ} \mathrm{C}$, which is $20^{\circ} \mathrm{C}$ higher than the initial reaction temperature of the raw material $\mathrm{BP}$, and reaches the maximum reaction rate at $255^{\circ} \mathrm{C}$, which is $50^{\circ} \mathrm{C}$ higher than the maximum reaction rate of $\mathrm{BP}$, and the reaction stops at about $300^{\circ} \mathrm{C}$. Even if the temperature is further increased, the residual rate of TGA is almost unchanged. The Tmax of all ANFs between $200-240^{\circ} \mathrm{C}$ was higher than that of $180^{\circ} \mathrm{C}$, which means that the thermal stability of ANFs after treatment was improved. The possible reason is that the hemicellulose with poor thermal stability was removed and the high content of lignin retained in the material. From the TEM image, it can be seen that the lignin covered with fiber formed a relatively stable carbon layer, which reduced the heat transfer efficiency. This supports the conclusion that the thermal stability was improved. $\mathrm{ZnCl}_{2}$ during pretreatment contributed to thermal stability. Higher thermal stability of the resulting samples may be due to the participation of $\mathrm{Cl}^{-}$in the reaction, so that the fiber formed a more stable network crosslinking structure.
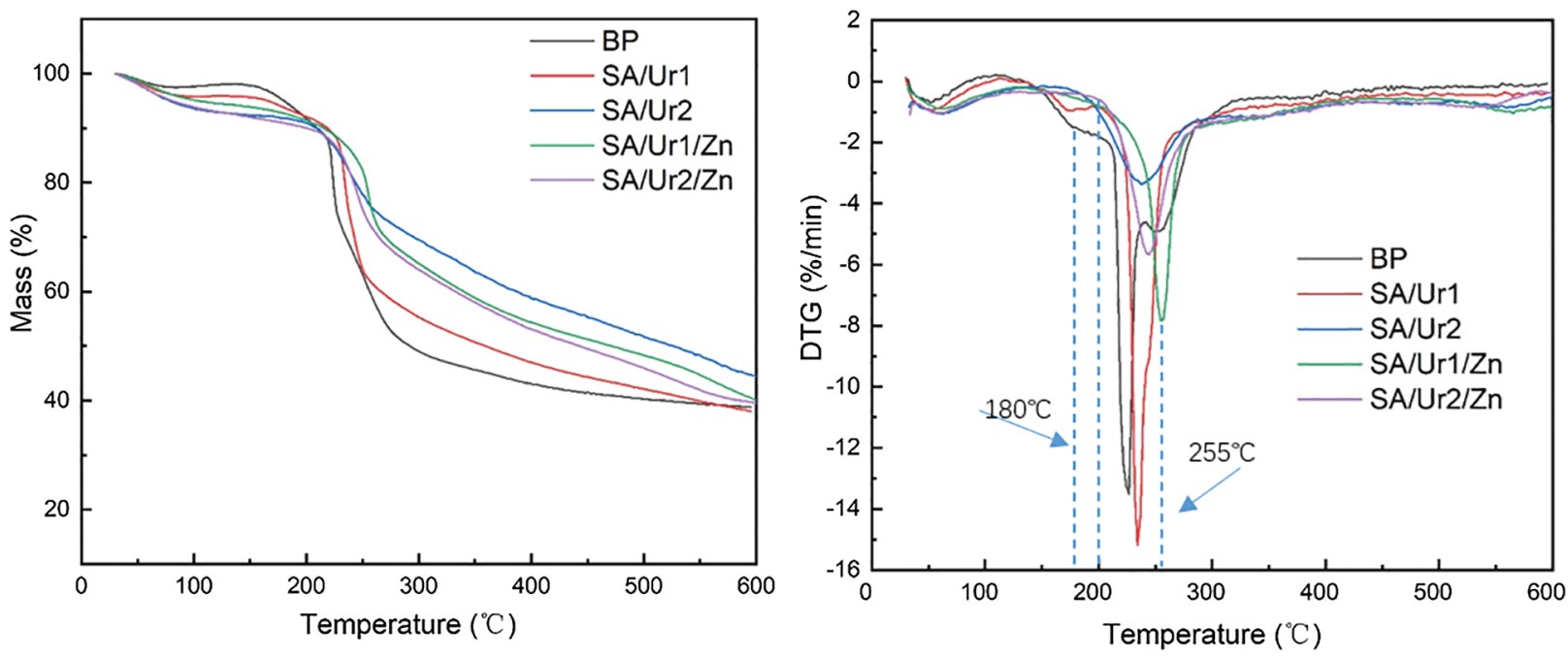

Figure 6: TGA and DTG images of BP and ANFs

\section{Conclusion}

The acid deep eutectic solvent (DES) was synthesized by using low-cost and common chemicals, amino sulfonic acid (SA) and urea (Ur), for sulfation of bamboo residues (BP) after high-temperature saturated steam treatment to the residual value. This study demonstrated that the DES was able to destroy the hydrogen bonds between the cellulose. After mild mechanical treatment, lignin-containing nanocellulose (ANFs) could be obtained with a yield of up to $75 \%$. The fiber in the ANFs is long and thin, with a width of about $3 \mathrm{~nm}$. The ANFs produced by the binary system is easier to form aggregates. Under the ternary system of $10 \mathrm{~nm}$, the distribution of ANFs fibers is more uniform, and some lignin particles reach nanometer level. The thermal stability of the ANFs obtained from binary DES is higher than that of the raw materials $\mathrm{BP}$, and the crystallinity decreases with the change of crystal form; in ternary DES, addition of $\mathrm{ZnCl}_{2}$ maintains the fiber I structure, and improves the thermal stability of the ANFs which is better than that of the binary system. ANFS maintains the structure of the fiber I and has high crystallinity, good hydrophilicity, low density, good biodegradability and biocompatibility as well as stable chemical 
properties. A large number of hydroxyl groups are exposed on the surface of ANFS, which makes nanocellulose have great potential for chemical modification.

Acknowledgement: All authors contributed equally to this work.

Funding Statement: The authors would like to thank for the financial support from the National Natural Science Foundation of China (No. 31901374); Foundation of High-level Talents of Anhui Province (18030701150).

Conflicts of Interest: The authors declare that they have no conflicts of interest to report regarding the present study.

\section{References}

1. Wang, Z., Li, H., Lorenzo, R., Corbi, I., Corbi, O. et al. (2020). Review on bond properties between wood and fiber reinforced polymer. Journal of Renewable Materials, 8(8), 993-1018. DOI 10.32604/jrm.2020.012488.

2. Corbi, I., Corbi, O., Li, H. T. (2019). A coupled control strategy for the mitigation of structural vibrations. Ingegneria Sismica, 36(3), 107-115.

3. Corbi, I., Corbi, O., Li, H. T. (2020). Convolutive PD controller for hybrid improvement of dynamic structural systems. Soil Dynamics and Earthquake Engineering, 137(6), 106255. DOI 10.1016/j.soildyn.2020.106255.

4. Li, H. T., Su, J. W., Xiong, Z. H., Ashraf, M., Corbi, I. et al. (2020). Evaluation on the ultimate bearing capacity for laminated bamboo lumber columns under eccentric compression. Structures, 28, 1572-1579. DOI 10.1016/j. istruc.2020.10.004.

5. Tan, C., Li, H. T., Ashraf, M., Corbi, I., Corbi, O. et al. (2021). Evaluation of axial capacity of engineered bamboo columns. Journal of Building Engineering, 34, 102039. DOI 10.1016/j.jobe.2020.102039.

6. Wang, Z., Li, H. T., Fei, B. H., Ashraf, M., Xiong, Z. H. et al. (2021). Axial compressive performance of laminated bamboo column with aramid fiber reinforced polymer. Composite Structures, 258, 113398. DOI 10.1016/j. compstruct.2020.113398.

7. Yang, D., Li, H. T., Xiong, Z. H., Mimendi, L., Lorenzo, R. et al. (2020). Mechanical properties of laminated bamboo under off-axis compression. Composites Part A: Applied Science and Manufacturing, 138, 106042. DOI 10.1016/j.compositesa.2020.106042.

8. Zhou, K., Li, H. T., Hong, C. K., Ashraf, M., Sayed, U. et al. (2021). Mechanical properties of large-scale parallel bamboo strand lumber under local compression. Construction and Building Materials, 271, 121572. DOI 10.1016/ j.conbuildmat.2020.121572.

9. He, M. X., Wang, J. L., Qin, H., Shui, Z. X., Zhu, Q. L. et al. (2014). Bamboo: A new source of carbohydrate for biorefinery. Carbohydrate Polymers, 111, 645-54. DOI 10.1016/j.carbpol.2014.05.025.

10. Wang, Z., Li, H. T., Yang, D., Xiong, Z. H., Sayed, U. et al. (2021). Bamboo node effect on the tensile properties of side press-laminated bamboo lumber. Wood Science and Technology, 55(1), 195-214. DOI 10.1007/s00226-020-01251-9.

11. Hu, K., Huang, Y. H., Fei, B. H., Yao, C. L., Zhao, C. et al. (2017). Investigation of the multilayered structure and microfibril angle of different types of bamboo cell walls at the micro/nano level using a LC-polScope imaging system. Cellulose, 24(11), 4611-4625. DOI 10.1007/s10570-017-1447-y.

12. Wang, X. Z., Chen, D. L., Huang, X. N., Song, L. L., Gu, W. L. et al. (2020). Effect of high-temperature saturated steam treatment on the physical, chemical, and mechanical properties of moso bamboo. Journal of Wood Science, 66(1), 52. DOI 10.1186/s10086-020-01899-8.

13. Li, P., Sirvio, J. A., Haapala, A., Liimatainen, H. (2017). Cellulose nanofibrils from nonderivatizing urea-based deep eutectic solvent pretreatments. Applied Materials \& Interfaces, 9(3), 2846-2855. DOI 10.1021/acsami.6b13625.

14. Ling, Z., Edwards, V. J., Guo, Z. W., Prevost, N. T., Nam, S. H. et al. (2018). Structural variations of cotton cellulose nanocrystals from deep eutectic solvent treatment: Micro and nano scale. Cellulose, 26(2), 861-876. DOI 10.1007/s10570-018-2092-9. 
15. Sirviö, J. A., Ukkola, J., Liimatainen, H. (2019). Direct sulfation of cellulose fibers using a reactive deep eutectic solvent to produce highly charged cellulose nanofibers. Cellulose, 26(4), 2303-2316. DOI 10.1007/s10570-019-02257-8.

16. Yu, W., Wang, C. Y., Yi, Y. J., Zhou, W. L. (2019). Choline chloride-based deep eutectic solvent systems as a pretreatment for nanofibrillation of ramie fibers. Cellulose, 26(5), 3069-3082. DOI 10.1007/s10570-019-02290-7.

17. Hong, S., Yuan, Y., Li, P. P., Zhang, K. T., Lian, H. L. et al. (2020). Enhancement of the nanofibrillation of birch cellulose pretreated with natural deep eutectic solvent. Industrial Crops and Products, 154, 112677. DOI 10.1016/ j.indcrop.2020.112677.

18. Hong, S., Song, Y. D., Yuan, Y., Lian, H. L., Liimatainen, H. et al. (2020). Production and characterization of lignin containing nanocellulose from luffa through an acidic deep eutectic solvent treatment and systematic fractionation. Industrial Crops and Products, 143, 111913. DOI 10.1016/j.indcrop.2019.111913.

19. Herrera, M., Thitiwutthisakul, K., Yang, X., Rujitanaroj, P., Rojas, R. et al. (2018). Preparation and evaluation of high-lignin content cellulose nanofibrils from eucalyptus pulp. Cellulose, 25(5), 3121-3133. DOI 10.1007/ s10570-018-1764-9.

20. Mosier, N., Wyman, C., Dale, B., Elander, R., Lee, Y. Y. et al. (2005). Features of promising technologies for pretreatment of lignocellulosic biomass. Bioresource Technology, 96(6), 673-686. DOI 10.1016/j. biortech.2004.06.025.

21. Alvira, P., Pejó, E. T., Ballesteros, M., Negro, M. J. (2010). Pretreatment technologies for an efficient bioethanol production process based on enzymatic hydrolysis: A review. Bioresource Technology, 101(13), 4851-61. DOI 10.1016/j.biortech.2009.11.093.

22. Sun, Y., Cheng, J. Y. (2002). Hydrolysis of lignocellulosic materials for ethanol production: A review. Bioresource Technology, 83, 1-11. DOI 10.1016/S0960-8524(01)00212-7.

23. Zdanowicz, M., Wilpiszewska, K., Spychaj, K. T. (2018). Deep eutectic solvents for polysaccharides processing. A review. Carbohydrate Polymers, 200, 361-380. DOI 10.1016/j.carbpol.2018.07.078.

24. Jeong, K. M., Lee, M. S., Nam, M. W., Zhao, J., Jin, Y. et al. (2015). Tailoring and recycling of deep eutectic solvents as sustainable and efficient extraction media. Journal of Chromatography A, 1424, 10-17. DOI 10.1016/j.chroma.2015.10.083.

25. Zdanowicz, M., Spychaj, T., Maka, H. (2016). Imidazole-based deep eutectic solvents for starch dissolution and plasticization. Carbohydrate Polymers, 140, 416-423. DOI 10.1016/j.carbpol.2015.12.036.

26. Azizi, N., Alipour, M. (2015). Eco-efficiency and scalable synthesis of bisamides in deep eutectic solvent. Journal of Molecular Liquids, 206, 268-271. DOI 10.1016/j.molliq.2015.02.033.

27. Wang, Q., Yao, X. Q., Geng, Y. R., Zhou, Q., Lu, X. M. et al. (2015). Deep eutectic solvents as highly active catalysts for the fast and mild glycolysis of poly(ethylene terephthalate)(PET). Green Chemistry, 17(4), 24732479. DOI 10.1039/C4GC02401J.

28. Jiang, J., Nancy, C., Carrillo, E., Oguzlu, H., Han, X. S. et al. (2020). High production yield and more thermally stable lignin-containing cellulose nanocrystals isolated using a ternary acidic deep eutectic solvent. ACS Sustainable Chemistry \& Engineering, 8(18), 7182-7191. DOI 10.1021/acssuschemeng.0c01724.

29. Sirviö, J. A., Visanko, M., Liimatainen, H. (2015). Deep eutectic solvent system based on choline chloride-urea as a pretreatment for nanofibrillation of wood cellulose. Green Chemistry, 17(6), 3401-3406. DOI 10.1039/C5GC00398A.

30. Kalia, S., Visanko, M., Liimatainen, H. (2011). Cellulose-based Bio- and nanocomposites: A review. International Journal of Polymer Science, 2011, 35. DOI 10.1155/2011/837875.

31. Spence, K. L., Venditti, R. A., Habibi, Y., Rojas, O. J., Pawlak, J. J. et al. (2010). The effect of chemical composition on microfibrillar cellulose films from wood pulps: Mechanical processing and physical properties. Bioresource Technology, 101(15), 5961-5968. DOI 10.1016/j.biortech.2010.02.104.

32. Bian, H., Dong, M., Chen, L. D., Zhou, X. L., Wang, R. B. et al. (2020). On-demand regulation of lignocellulosic nanofibrils based on rapid fractionation using acid hydrotrope: Kinetic study and characterization. ACS Sustainable Chemistry \& Engineering, 8(25), 9569-9577. DOI 10.1021/acssuschemeng.0c02968.

33. Saputra, R., Walvekar, R., Khalid, M., Mubarak, N. M. (2020). Synthesis and thermophysical properties of ethylammonium chloride-glycerol-znCl2 ternary deep eutectic solvent. Journal of Molecular Liquids, 310, 113232. DOI 10.1016/j.molliq.2020.113232. 
34. Sluiter, J. B., Ruiz, R. O., Scarlata, C. J., Sluiter, A. D., Templeton, D. W. et al. (2010). Compositional analysis of lignocellulosic feedstocks. 1. review and description of methods. Journal of Agricultural and Food Chemistry, 58(16), 9043-53. DOI 10.1021/jf1008023.

35. Sluiter, A., Hames, B., Ruiz, R. O., Scarlata, C., Sluiter, J. et al. (2012). Determination of structural carbohydrates and lignin in biomass. Technical Report, 834, 510-42618.

36. Chen, L., Yu, Q., Wang, Q., Wang, W., Qi, W. et al. (2019). A novel deep eutectic solvent from lignin-derived acids for improving the enzymatic digestibility of herbal residues from cellulose. Cellulose, 26(3), 1947-1959. DOI 10.1007/s10570-018-2190-8.

37. Liu, Y. Z., Chen, W. S., Xia, Q. Q., Guo, B. T., Wang, Q. W. et al. (2017). Efficient cleavage of lignin-carbohydrate complexes and ultrafast extraction of lignin oligomers from wood biomass by microwave-assisted treatment with deep eutectic solvent. ChemSusChem, 10(8), 1692-1700. DOI 10.1002/cssc.201601795.

38. Liu, Q., Yuan, T., Fu, Q. J., Bai, Y. Y., Peng, F. et al. (2019). Choline chloride-lactic acid deep eutectic solvent for delignification and nanocellulose production of moso bamboo. Cellulose, 26(18), 9447-9462. DOI 10.1007/ s10570-019-02726-0.

39. Levdansky, V. A., Kondracenko, A. S., Levdansky, A. V., Kuznetsov, B. N., Djakovitch, L. et al. (2014). Sulfation of microcrystalline cellulose with sulfamic acid in N,N-dimethylformamide and diglyme. Journal of the American Chemical Society, 2, 162-169. 